Acta Crystallographica Section E

Structure Reports

Online

ISSN 1600-5368

\section{Graham Smith, ${ }^{\text {a* Urs D. }}$ Wermuth $^{\mathbf{b}}$ and Jonathan $M$. White $^{c}$}

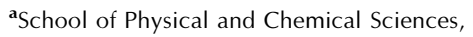
Queensland University of Technology, GPO Box 2434, Brisbane, Queensland 4001, Australia, ${ }^{\mathbf{b}}$ School of Science, Griffith University, Nathan, Queensland 4111, Australia, and ${ }^{\mathrm{C}} \mathrm{BIO}-21$ Molecular Science and Biotechnology, School of Chemistry, University of Melbourne, Australia

Correspondence e-mail: g.smith@qut.edu.au

\section{Key indicators}

Single-crystal X-ray study

$T=130 \mathrm{~K}$

Mean $\sigma(\mathrm{C}-\mathrm{C})=0.002 \AA$

$R$ factor $=0.030$

$w R$ factor $=0.082$

Data-to-parameter ratio $=9.8$

For details of how these key indicators were automatically derived from the article, see http://journals.iucr.org/e.

\title{
Anhydrous guanidinium 3,5-dinitrobenzoate
}

Guanidinium 3,5-dinitrobenzoate, $\mathrm{CH}_{6} \mathrm{~N}_{3}{ }^{+} \cdot \mathrm{C}_{7} \mathrm{H}_{3} \mathrm{~N}_{2} \mathrm{O}_{6}{ }^{-}$, determined at $130 \mathrm{~K}$, forms a three-dimensional hydrogen-bonded structure involving all six $\mathrm{H}$ atoms of the guanidinium cation with oxygen acceptors of the anion including an offset cyclic $R_{2}^{2}(8)$ interaction with the carboxylate group.

\section{Comment}

Guanidine (GU) reacts with most carboxylic acids but the number of crystallographically characterized examples of these salts is not large. With aromatic and heteroaromatic acids, most compounds are anhydrous, e.g. guanidinium 4amino-3,5,6-trichloropicolinate (Parthasarathi et al., 1982), guanidinium 3,5-dinitrosalicylate (Smith et al., 2001), guanidinium 4-hydroxypyridinium-2,6-dicarboxylate (Moghimi et al., 2005) and bis(guanidinium) pyromellitate (Sun et al., 2002). Hydrate examples are the compounds with pyrazine2,3-dicarboxylic acid (a 2:1 trihydrate) (Smith et al., 2006) and 4-nitroanthranilic acid (a 1:1 monohydrate) (Smith et al., 2007).<smiles>NC(N)=[NH2+]</smiles><smiles>O=[N+]([O-])c1cc([N+](=O)[O-])cc([N+](=O)[O-])c1</smiles>

(I)

Although 3,5-dinitrobenzoic acid (3,5-DNBA) has been used for the synthesis of crystalline designer compounds (Etter \& Frankenbach, 1989), the structure of the guanidiniun salt has not previously been reported. We obtained large crystals of the title compound, anhydrous guanidinium 3,5dinitrobenzoate, $\left[\mathrm{CH}_{6} \mathrm{~N}_{3}\right]^{+}\left[\mathrm{C}_{7} \mathrm{H}_{3} \mathrm{~N}_{3} \mathrm{O}_{6}\right]^{-}$, (I), from the $1: 1$ stoichiometric reaction of 3,5-DNBA with guanidine carbonate in $50 \%$ propan-2-ol-water and the crystal structure is reported here.

In (I) (Fig. 1), all six $\mathrm{H}$ atoms of the $\mathrm{GU}$ cation give hydrogen-bonding interactions with carboxylate and, to a lesser extent, nitro $\mathrm{O}$ acceptors of the anion (Table 1), resulting in a three-dimensional framework structure (Fig. 2). Among these is a cyclic $R_{2}^{2}(8)$ interaction with the two carboxylate oxygen acceptors of the anion, similar to that found in the analogous guanidinium 3,5-dinitrosalicylate, except that the two interacting species are offset rather than coplanar. In (I) both carboxylate $\mathrm{O}$ atoms also act as acceptors in secondary hydrogen-bonding interactions.
Received 14 December 2006 Accepted 16 January 2007 
In the 3,5-DNBA anions both the carboxylate and the nitro groups are rotated slightly out of the plane of the benzene ring [torsion angles: $\mathrm{C} 2-\mathrm{C} 1-\mathrm{C} 7-\mathrm{O} 71=165.45(12)^{\circ}, \mathrm{C} 2-\mathrm{C} 3-$ $\mathrm{N} 3-\mathrm{O} 32=-174.96(11)^{\circ}$ and $\mathrm{C} 4-\mathrm{C} 5-\mathrm{N} 5-\mathrm{O} 52=$ $\left.166.42(11)^{\circ}\right]$.

\section{Experimental}

The title compound was synthesized by heating together $1 \mathrm{mmol}$ quantities of 3,5-dinitrobenzoic acid (3,5-DNBA) and guanidinium carbonate in $50 \mathrm{ml}$ of $50 \%$ propan-2-ol-water under reflux for 10 minutes. After concentration to $\mathrm{ca} 30 \mathrm{ml}$, partial room-temperature evaporation of the hot-filtered solution gave pale-yellow crystal blocks (m.p. > $553 \mathrm{~K}$ ).

\section{Crystal data \\ $\mathrm{CH}_{6} \mathrm{~N}_{3}{ }^{+} \cdot \mathrm{C}_{7} \mathrm{H}_{3} \mathrm{~N}_{2} \mathrm{O}_{6}{ }^{-}$ \\ $M_{r}=271.20$ \\ Monoclinic, $P 2_{b} / n$ \\ $a=7.5192(6) \mathrm{A}$ \\ $b=19.0605(14) \AA$ \\ $c=7.8416(6) \AA$ \\ $\beta=103.566(1)^{\circ}$ \\ $V=1092.50(15) \AA^{3}$}

$$
\begin{aligned}
& Z=4 \\
& D_{x}=1.649 \mathrm{Mg} \mathrm{m}^{-3} \\
& \text { Mo } K \alpha \text { radiation } \\
& \mu=0.14 \mathrm{~mm}^{-1} \\
& T=130(2) \mathrm{K} \\
& \text { Block, pale yellow } \\
& 0.35 \times 0.30 \times 0.20 \mathrm{~mm}
\end{aligned}
$$

\section{Data collection}

Bruker SMART CCD area-detector diffractometer

$\varphi$ and $\omega$ scans

Absorption correction: none

5679 measured reflections

$$
\begin{aligned}
& 1920 \text { independent reflections } \\
& 1753 \text { reflections with } I>2 \sigma(I) \\
& R_{\text {int }}=0.042 \\
& \theta_{\max }=25.0^{\circ}
\end{aligned}
$$

\section{Refinement}

Refinement on $F^{2}$

$R\left[F^{2}>2 \sigma\left(F^{2}\right)\right]=0.030$

$w R\left(F^{2}\right)=0.082$

$S=1.03$

1920 reflections

196 parameters

$\mathrm{H}$ atoms treated by a mixture of

independent and constrained

refinement

Table 1

Hydrogen-bond geometry $\left(\AA,^{\circ}\right)$.

\begin{tabular}{lllll}
\hline$D-\mathrm{H} \cdots A$ & $D-\mathrm{H}$ & $\mathrm{H} \cdots A$ & $D \cdots A$ & $D-\mathrm{H} \cdots A$ \\
\hline $\mathrm{N} 11-\mathrm{H} 11 A \cdots \mathrm{O} 71^{\mathrm{i}}$ & $0.853(16)$ & $2.035(15)$ & $2.8376(16)$ & $156.6(14)$ \\
$\mathrm{N} 11-\mathrm{H} 11 B \cdots \mathrm{O} 72^{\mathrm{ii}}$ & $0.889(16)$ & $1.919(15)$ & $2.7933(17)$ & $167.4(15)$ \\
$\mathrm{N} 21-\mathrm{H} 21 A \cdots \mathrm{O} 51^{\mathrm{iii}}$ & $0.857(15)$ & $2.549(15)$ & $3.1979(15)$ & $133.3(11)$ \\
$\mathrm{N} 21-\mathrm{H} 21 B \cdots \mathrm{O} 71$ & $0.887(17)$ & $1.966(17)$ & $2.8499(15)$ & $174.2(15)$ \\
$\mathrm{N} 31-\mathrm{H} 31 A \cdots \mathrm{O} 72$ & $0.837(15)$ & $2.182(15)$ & $3.0017(16)$ & $166.5(14)$ \\
$\mathrm{N} 31-\mathrm{H} 31 B \cdots \mathrm{O} 32^{\text {iv }}$ & $0.830(16)$ & $2.590(16)$ & $3.1371(16)$ & $124.7(13)$ \\
$\mathrm{N} 31-\mathrm{H} 31 B \cdots \mathrm{O} 71^{\mathrm{i}}$ & $0.830(16)$ & $2.422(16)$ & $3.0954(16)$ & $138.9(13)$ \\
\hline
\end{tabular}

Symmetry codes: (i) $\quad x+\frac{1}{2},-y+\frac{3}{2}, z+\frac{1}{2} ; \quad$ (ii) $\quad x-\frac{1}{2},-y+\frac{3}{2}, z+\frac{1}{2}$; $\quad$ (iii) $-x,-y+1,-z+1$; (iv) $-x+\frac{3}{2}, y+\frac{1}{2},-z+\frac{1}{2}$.

$\mathrm{H}$ atoms involved in hydrogen-bonding interactions were located by difference Fourier methods and their positional and isotropic displacement parameters were refined. The aromatic $\mathrm{H}$ atoms were included in the refinement in calculated positions $(\mathrm{C}-\mathrm{H}=0.95 \AA)$ using a riding-model approximation, with $U_{\text {iso }}(\mathrm{H})=1.2 U_{\text {eq }}(\mathrm{C})$.

Data collection: SMART (Bruker, 2000); cell refinement: SAINT (Bruker, 1999); data reduction: $S A I N T$; program(s) used to solve

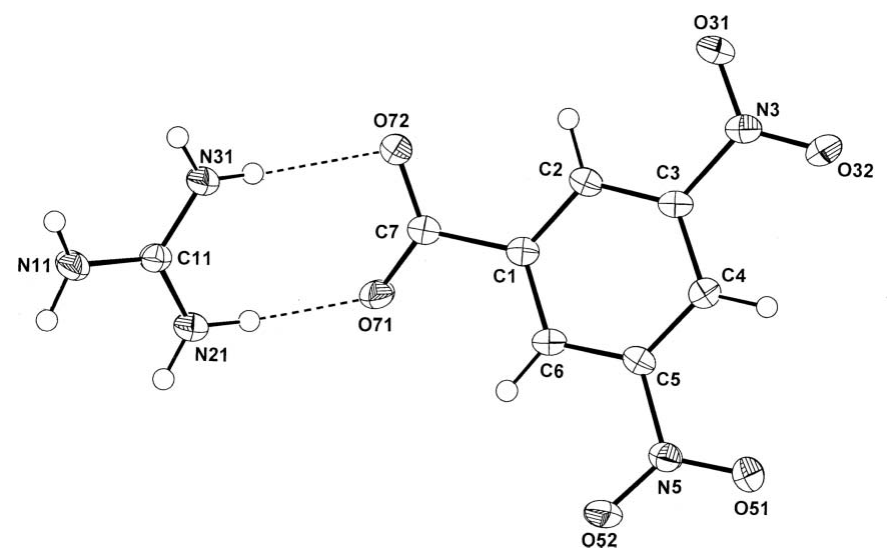

Figure 1

The structure, atom-naming scheme and inter-species hydrogen bonding (shown as dashed lines) for the GU cation and the DNBA anion in (I). Displacement ellipsoids are drawn at the $50 \%$ probability level.

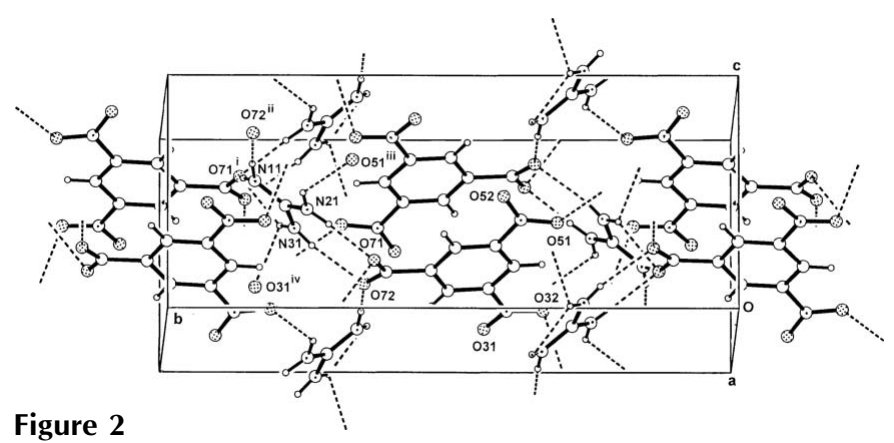

Perspective view of the packing of (1) in the unit cell viewed approximately down the approximate $a$ axial direction, showing hydrogen-bonding associations. For symmetry codes, see Table 1 .

structure: SHELXS97 (Sheldrick, 1997); program(s) used to refine structure: SHELXL97 (Sheldrick, 1997); molecular graphics: PLATON (Spek, 2003); software used to prepare material for publication: PLATON.

The authors acknowledge financial support from the School of Physical and Chemical Sciences, Queensland University of Technology, and the School of Chemistry, University of Melbourne.

\section{References}

Bruker (1999). SAINT. Version 6.02. Bruker AXS Inc., Madison, Wisconsin, USA.

Bruker (2000). SMART. Version 5.55. Bruker AXS Inc., Madison, Wisconsin, USA.

Etter, M. C. \& Frankenbach, G. M. (1989). Chem. Mater. 1, 10-12.

Moghimi, A., Aghabozorg, H., Soleimannejad, J. \& Ramezanipour, F. (2005). Acta Cryst. E61, o442-o444.

Parthasarathi, V., Wolfrum, S., Noordik, J. H., Beurskins, P. T., Smith, G., O'Reilly, E. J. \& Kennard, C. H. L. (1982). Cryst. Struct. Commun. 11, 1519 1524.

Sheldrick, G. M. (1997). SHELXL97 and SHELXS97, University of Göttingen, Germany.

Smith, G., Bott, R. C. \& Wermuth, U. D. (2001). Acta Cryst. E57, o640-o642. Smith, G., Wermuth, U. D., Healy, P. C. \& White, J. M. (2007). Acta Cryst. E63, 07-09.

Smith, G., Wermuth, U. D., Young, D. J. \& White, J. M. (2006). Acta Cryst. E62, o3912-03914.

Spek, A. L. (2003). J. Appl. Cryst. 36, 7-13.

Sun, Y.-Q., Zhang, J. \& Yang, G.-Y. (2002). Acta Cryst. E58, o904-o906. 